\title{
Nocturnal melatonin plasma levels in patients with OSAS: the effect of CPAP
}

\author{
C. Hernández*,\#, J. Abreu**\#, P. Abreu¡, A. Castro* and A. Jiménez
}

\begin{abstract}
Melatonin is a pineal hormone that regulates the human cycle of sleep and wakefulness. Plasma melatonin levels were investigated in patients with obstructive sleep apnoea syndrome (OSAS).
\end{abstract}

In total, 20 patients with OSAS and 11 healthy controls were studied. OSAS patients were tested twice: on the night of diagnostic polysomnography and the night of continuous positive airway pressure (CPAP) titration. Controls were tested on one occasion. Plasma melatonin levels were determined at 23:00 $\mathrm{h}$ (light period), at 02:00 $\mathrm{h}$ (dark period) and at 06:00 $\mathrm{h}$ (light period) in patients and control subjects using the radioimmunoassay method.

The control subjects showed a nocturnal melatonin peak value at 02:00 $\mathrm{h}\left(70.6 \pm 14 \mathrm{pg} \cdot \mathrm{mL}^{-1}\right)$. However, this nocturnal melatonin peak was absent in the OSAS patients. The highest melatonin value was found in OSAS patients on the night of diagnosis, at 06:00 h $\left(49.3 \pm 36.8 \mathrm{pg} \cdot \mathrm{mL}^{-1}\right)$. It was found that the melatonin level in OSAS patients at 06:00 $\mathrm{h}$ was significantly lower in the night of titration $\left(35.6 \pm 37.9 \mathrm{pg} \cdot \mathrm{mL}^{-1}\right)$ than in the diagnosis night. However, the melatonin levels at either 23:00 $\mathrm{h}$ or 02:00 $\mathrm{h}$ in OSAS patients did not differ significantly when comparing levels in the night of diagnostic polysomnography $\left(23: 00 \mathrm{~h}: 31.6 \pm 29.8 \mathrm{pg} \cdot \mathrm{mL}^{-1} ; 02: 00 \mathrm{~h}: 47.4 \pm 33.8 \mathrm{pg} \cdot \mathrm{mL}^{-1}\right)$ with levels in the night of CPAP titration $\left(23: 00 \mathrm{~h}: 20.2 \pm 10.3 \mathrm{pg} \cdot \mathrm{mL}^{-1} ; 02: 00 \mathrm{~h}: 37.7 \pm 27.5 \mathrm{pg} \cdot \mathrm{mL}^{-1}\right)$.

Patients with obstructive sleep apnoea syndrome have an abnormal melatonin secretion pattern. The absence of a nocturnal serum melatonin peak could be partially related to the difficulty that these patients have in achieving a normal sleep-wakefulness pattern.

KEYWORDS: Continuous positive airway pressure titration, melatonin secretion, obstructive sleep apnoea syndrome

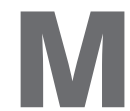
elatonin is a hormone secreted by the pineal gland in a cyclic pattern [1]. Levels of melatonin are under the control of the suprachiasmatic nucleus and vary according to the daily cycle. Melatonin levels are higher during the night and lower during the day [2] Exposure to light during the night, when melatonin levels are higher, abruptly curtails pineal melatonin production and causes a rapid decline in tissue and blood levels of this hormone [3].

It has been claimed that melatonin has sleeppromoting properties [4] and that it also has an important role in the regulation of body temperature [5]. In humans, light exposure during the night can acutely suppress melatonin levels. Even moderate light intensities, similar to indoor intensities, are able to cause substantial suppression of melatonin production [6]. While light is the most important environmental factor influencing melatonin levels, various drugs, such as $\beta$-blockers, can also profoundly affect melatonin levels [7]. Also since the mid-1990s, studies have demonstrated a crucial role for melatonin as a mediator between the thermoregulatory and arousal system in humans [8].

Obstructive sleep apnoea syndrome (OSAS) is a common disorder in the adult population characterised by repetitive obstruction of the upper airway during sleep, resulting in an episodic hypoxaemia and disturbed sleep at night. OSAS is associated with excess of mortality $[9,10]$ and contributes to the impairment of health-related quality of life [11]. Treatment with continuous positive airway pressure (CPAP) can eliminate apnoeas and can improve the quality of sleep. Little is known about melatonin levels in OSAS patients. WIKNER et al. [12] did not find differences between melatonin secretion in OSAS patients before and after CPAP. UlFBERG et al. [13] showed that OSAS patients presented higher melatonin levels in the afternoon than control subjects who did not snore. Finally, BRZECKA et al. [14] found a correlation between OSAS severity and peak night-time melatonin value.
AFFILIATIONS

*Service of Pneumology, and,

${ }^{\text {\#}}$ Research Unit, Hospital

Universitario de Canarias, and

"Dept of Physiology, Faculty of

Medicine, University of La Laguna, La

Laguna, Tenerife, Spain.

CORRESPONDENCE

C. Hernández

Service of Pneumology

Hospital Universitario de Canarias

Urbanización Ofra s/n

E-38320 La Laguna

Tenerife

Spain

Fax: 34922600562

E-mail: chernandezg@teleline.es

Received:

April 162006

Accepted after revision:

May 162007

STATEMENT OF INTEREST

None declared.

European Respiratory Journal

Print ISSN 0903-1936

Online ISSN 1399-3003 
$\beta$-Adrenoceptor stimulation by endogenously released norepinephrine (NE) seems to account for $\sim 85 \%$ of nocturnal melatonin levels, whereas the remainder is presumably due to an interaction of catecholamine with the pinealocyte $\alpha$-receptor [15]. Some studies have shown an increase in catecholamine levels in OSAS patients [16] that can be reduced by CPAP treatment [17].

The aim of the present study was to determine the relationship between plasma melatonin levels in patients with OSAS before treatment with levels at three time-points during the CPAP titration night.

\section{METHODS}

\section{Study population}

The study population consisted of 20 consecutive patients with symptoms suggestive of OSAS (e.g. breathing interruptions reported by sleeping partners, snoring and daytime sleepiness (Epworth Sleepiness Scale (ESS) >10)), a polysomnography apnoea/hypopnoea index (AHI) $>10$ and a clinical indication for CPAP treatment according to the Spanish Society of Pneumology and Thoracic Surgery [18]. In addition, 11 ageand sex-matched healthy control subjects were studied. These were recruited from hospital staff without breathing interruptions, snoring or daytime sleepiness $(\mathrm{ESS}<6)$, and with an AHI $<5$. None of the patients or control subjects had any significant comorbilities that may have affected their sleep-wake behaviour or circadian system. They had normal kidney and liver function and none of them took sedatives, anti-epileptic drugs, tricyclic antidepressants or any medication known to influence melatonin metabolism. Due to their possible effects on melatonin synthesis, subjects with psychiatric disorders (e.g. depression) or sleep disorders (other than OSAS in the patient group; e.g. insomnia, circadian disorders, infectious or endocrine illness, shift workers or subjects with jet-lag syndrome) were excluded from the study. Patients actively abusing alcohol were also excluded. All patients and controls had the same self-reported baseline sleep-wake schedules (they slept from 23:00-24:00 $\mathrm{h}$ to 06:00-07:00 $\mathrm{h}$ the next day) and also had the same circadian preference (dark cycle from 23:00-24:00 $\mathrm{h}$ to 06:00-07:00 $\mathrm{h}$ and light cycle the rest of the day). The characteristics of the 20 patients and the 11 healthy control subjects enrolled in the study are given in table 1 . They did not differ significantly in age and body mass index. The sex distribution of patients and controls were similar.

\begin{tabular}{|c|c|c|c|}
\hline \multirow[t]{2}{*}{ TABLE 1} & \multicolumn{3}{|c|}{$\begin{array}{l}\text { Characteristics of patients and controls enrolled } \\
\text { in the study }\end{array}$} \\
\hline & OSAS patients & Control subjects & $p$-value \\
\hline Age yrs & $51.3 \pm 10.64$ & $48.9 \pm 8.9$ & NS \\
\hline BMI $\mathbf{k g} \cdot \mathrm{m}^{-2}$ & $31.9 \pm 5.6$ & $29.6 \pm 4.6$ & NS \\
\hline Male/female n & $16 / 4$ & $9 / 2$ & \\
\hline ESS & $12.1 \pm 4.2$ & $4.5 \pm 2.4$ & $<0.05$ \\
\hline
\end{tabular}

All patients and healthy volunteers were fully informed of the purpose of the study and gave voluntary consent to take part in the investigation. The study was approved by the Local Human Research Ethics Committee of the Hospital Universitario de Canarias (HUC; Tenerife, Spain).

\section{Study design}

An open, nonrandomised clinical trial with control group and repeated measures was carried out in the Sleep Unit of the HUC from July 2004-July 2005. OSAS patients were tested twice: on the night of diagnostic polysomnography and the night of CPAP titration. Controls were tested on one occasion. Plasma melatonin levels were determined at 23:00 h (light period), 02:00 $\mathrm{h}$ (dark period) and 06:00 $\mathrm{h}$ (light period) in patients and control subjects using the radioimmunoassay (RIA) method.

\section{Study protocol}

Subjects were studied under carefully controlled conditions in the Pneumology Sleep Unit of the HUC. Each room is isolated from external light and noise. The ambient lighting conditions are similar to the normal light-dark cycle. The daily light period in the sleep unit is $17 \mathrm{~h}(1,745 \pm 33 \mathrm{~lx})$ and the dark period $7 \mathrm{~h}(1.33 \pm 0.3 \mathrm{~lx})$. At 23:00 h, the patients and control subjects went to bed and the white light was turned off until 06:00 h the following day. Light intensity was measured using a portable luminometer, at the level of the subject's face. Blood samples for measurement of melatonin were collected at 23:00 $\mathrm{h}$ and 06:00 $\mathrm{h}$ (light period), and 02:00 $\mathrm{h}$ (dark period). Blood samples were carried out from an antecubital vein, which was kept open at night by a normal saline drip. Serum samples were aliquoted into several tubes and frozen at $-30^{\circ} \mathrm{C}$ until analysis. Nocturnal blood sampling (02:00 h) was carried out by a trained nurse, with the help of a minute torch with a dim red light (intensity $<30 \mathrm{~lx}$ ) to avoid any direct light in patients' faces while they were sleeping. At 6:00 h, blood samples were collected while subjects were awake, $\sim 10 \mathrm{~min}$ after the lights were turned on; at 23:00 h blood samples were collected while subjects were awake.

All patients were monitored continuously for $\geqslant 7 \mathrm{~h}$ using a 19-channel polysomnograph (Somnostar alpha; Sensor Medic, Munich, Germany) placed in the sleep laboratory in the HUC. Electroencephalography (C4/A1 and C3/A2 placements), electrooculography and chin electromyography recordings were obtained with surface electrodes according to standard methods. Ventilatory airflow at the nose was registered with a nasal cannula and thermistor. Breathing movements of the chest and abdomen were monitored by inductive plethysmography. The arterial oxygen saturation $\left(\mathrm{Sa}_{\mathrm{a}} \mathrm{O}_{2}\right)$ was measured with pulse oximetry at the fingertip of the patient. Finally, an ECG was obtained. Analysis of sleep stages was performed manually at 30-s intervals according to the criteria of RECHTSCHAFFEN and KALES [19]. Apnoea was defined as a complete cessation of airflow for $>10 \mathrm{~s}$ and hypopnoea as a discernible $50 \%$ reduction in respiratory airflow accompanied by a decrease of $\geqslant 4 \%$ in oxyhaemoglobin saturation. The specific pattern of apnoeic episodes (central or obstructive) was not taken into account in the statistical analysis. The total number of scored apnoeas and hypopnoeas divided by the number of hours of sleep, referred to as the respiratory 
disturbance index (RDI), was determined for each participant. The respiratory arousal index (RAI) was defined as the number of arousals per hour of sleep. The proportion of total recorded (sleep) time with $\mathrm{Sa}_{1} \mathrm{O}_{2}<90 \%$ was also recorded.

In control subjects placed in the sleep laboratory of the HUC, cardiorespiratory signals (Embletta PDS Version 3.3; Somnologic Res Med, Sydney, Australia) were analysed via the same protocol as OSAS patients. Ventilatory airflow was measured via cannula and thermistor. Breathing movements were monitored by inductive plethysmography, $\mathrm{Sa}_{1} \mathrm{O}_{2}$ by pulse oximetry at the fingertip of the patient, and an ECG was obtained. Output from the portable diagnostic device was scored manually by the same sleep laboratory technician who scored the polysomnography, and with the same criteria.

\section{CPAP titration night}

On the night following the diagnosis study, the OSAS patients underwent CPAP titration with a commercially available CPAP device (REM Duo; Puritan Bennett, Pleasanton, CA, USA) at the sleep laboratory in the HUC. CPAP was applied via a nasal mask, and the pressure was increased progressively until the snoring and the majority of respiratory disturbances and respiration-related arousals in all sleep positions had ceased.

Blood samples were taken at 23:00 h, 02:00 h and 06:00 h, as during the diagnosis night. Serum samples were aliquoted into several tubes and stored at $-30^{\circ} \mathrm{C}$ until analysis. Melatonin levels in serum samples were measured by direct RIA using a ${ }^{125}$ I-MEL human kit (DRG International, Marburg, Germany) according to the manufacturer's instructions [20].

\section{Statistical analysis}

All the quantitative variables are expressed as mean \pm SD. A paired t-test was used for repeated measures to compare melatonin levels before and after CPAP treatment. In the control group, the differences between means were assessed using one-way ANOVA with the Tukey post hoc test. A p-value $<0.05$ was considered to be statistically significant.

\section{RESULTS}

The OSAS patients showed an RDI of $49 \pm 28.6 \cdot \mathrm{h}^{-1}$, an RAI of $31.7 \pm 21.8 \cdot \mathrm{h}^{-1}$ and a total sleep time with $\mathrm{Sa}_{1} \mathrm{O}_{2}<90 \%$ of

\begin{tabular}{|c|c|c|c|}
\hline \multirow[t]{2}{*}{ TABLE 2} & \multirow[b]{2}{*}{ Baseline indices } & \multirow[b]{2}{*}{ Titration indices } & \multirow[b]{2}{*}{ p-value } \\
\hline & & & \\
\hline RDI $h^{-1}$ & $49 \pm 28.6$ & $10.8 \pm 8.6$ & $<0.000$ \\
\hline RAI $h^{-1}$ & $31.7 \pm 21.8$ & $13.7 \pm 16.7$ & $<0.001$ \\
\hline TST \% with Sa, $\mathrm{O}_{2}<90 \%$ & $52.4 \pm 37.6$ & $24.4 \pm 32$ & $<0.000$ \\
\hline REM sleep \% & $10.3 \pm 7.3$ & $12 \pm 10.2$ & NS \\
\hline Sleep stages 3 and $4 \%$ & $26.1 \pm 15.4$ & $34.2 \pm 16.4$ & NS \\
\hline Efficiency \% & $81.2 \pm 9.5$ & $77.3 \pm 23.1$ & NS \\
\hline TST min & $274 \pm 61$ & $260 \pm 85$ & NS \\
\hline
\end{tabular}

Data are presented as mean $\pm \mathrm{SD}$. RDI: respiratory disturbance index; RAI: respiratory arousal index; TST: total sleep time; $\mathrm{Sa}_{2} \mathrm{O}_{2}$ : arterial oxygen saturation; REM: rapid eye movement.
$52.4 \pm 37.6 \%$. The RDI, RAI and total sleep time with $\mathrm{Sa}_{\mathrm{a}} \mathrm{O}_{2}$ $<90 \%$ all decreased significantly on the night of titration (table 2). There was no significant improvement in the total sleep time, rapid eye movement (REM) sleep nor sleep efficiency on the titration night in OSAS patients.

Control subjects showed an RDI of $2.6 \pm 1.2 \cdot \mathrm{h}^{-1}$ and a total sleep time with $\mathrm{Sa}_{\mathrm{a}_{2}}<90 \%$ of $0.3 \pm 0.2 \%$. Optimal CPAP pressure was achieved at 03:30 h, with a mean pressure of $0.83 \pm 0.07 \mathrm{kPa}\left(8.5 \pm 0.7 \mathrm{cmH}_{2} \mathrm{O}\right)$ in OSAS patients. Serum melatonin levels at 23:00 h (light period), 02:00 h (dark period) and $06: 00 \mathrm{~h}$ (light period) for patients and controls are given in table 3 and figure 1.

In control subjects, the melatonin level was $40.8 \pm 6.6 \mathrm{pg} \cdot \mathrm{mL}^{-1}$ at 23:00 h. It increased to $70.6 \pm 14.1 \mathrm{pg} \cdot \mathrm{mL}^{-1}$ at $02: 00 \mathrm{~h}$ and finally decreased to $44.7 \pm 9.9 \mathrm{pg} \cdot \mathrm{mL}^{-1}$ at $06: 00 \mathrm{~h}$.

In OSAS patients on the diagnosis night, the serum melatonin level at $23: 00 \mathrm{~h}$ was $31.6 \pm 29.9 \mathrm{pg} \cdot \mathrm{mL}^{-1}$; it increased to $47.4 \pm 33.8 \mathrm{pg} \cdot \mathrm{mL}^{-1}$ at $02: 00 \mathrm{~h}$ and finally, in contrast to control subjects, increased to $49.3 \pm 36.6 \mathrm{pg} \cdot \mathrm{mL}^{-1}$ at $06: 00 \mathrm{~h}$. For the titration night in OSAS patients, the melatonin level was $20.16 \pm 10.3 \mathrm{pg} \cdot \mathrm{mL}^{-1}$ at $23: 00 \mathrm{~h}$, which increased to $37.7 \pm$ $27.5 \mathrm{pg} \cdot \mathrm{mL}^{-1}$ at $02: 00 \mathrm{~h}$ and finally, in the same manner as control subjects, decreased to $35.6 \pm 37.9 \mathrm{pg} \cdot \mathrm{mL}^{-1}$ at $06: 00 \mathrm{~h}$.

In the control group (fig. 1a), melatonin showed a significant peak at 02:00 h. In OSAS patients (fig. 1b) on the diagnosis night, there was a different pattern with respect to the control group, because they did not present the melatonin peak value at 02:00 h. On the titration night, the highest melatonin level was measured at $02: 00 \mathrm{~h}$, in a similar manner to control subjects, but the melatonin levels did not drop as low as those seen in the control subjects. When the diagnosis and titration night were compared at each respective testing point in OSAS patients, only the 06:00 h point showed a significant difference $(\mathrm{p}<0.05)$. However, the OSAS patients never returned to a normal pattern of melatonin production.

\section{DISCUSSION}

The major finding of the present study is that in OSAS patients, the diagnosis night and titration night show a different serum melatonin pattern with respect to the control group. The melatonin secretion pattern in OSAS patients shows values in a plateau without the nocturnal peak found in healthy control subjects. Furthermore, at 06:00 h, the melatonin level in OSAS patients was lower on the titration night than on diagnosis night, but without a peak at 02:00 h, as seen in the control subjects.

In healthy subjects, there was a melatonin peak value at midnight and secretion was lowest in the afternoon [21]. Endogenous synthesis of melatonin during the night depends on $\beta$ - and $\alpha_{1}$-adrenergic receptor stimulation by NE [15]. In contrast, most studies focusing on patients with OSAS have shown elevated catecholamine levels [16], and although peripheral and central NE levels are not always well correlated, an increase in melatonin levels seems logical in OSAS patients at night, when NE levels are higher.

The current authors found significantly lower levels of melatonin at 06:00 $\mathrm{h}$ in OSAS patients on the CPAP titration night, compared with the diagnosis night, but not at 23:00 h or 


\begin{tabular}{|c|c|c|c|}
\hline TABLE 3 & $\begin{array}{l}\text { Melatonin le } \\
\text { syndrome }(0 \\
\text { subjects }\end{array}$ & $\begin{array}{l}\text { in obstructive } \\
\text { ) patients and }\end{array}$ & $\begin{array}{l}\text { ep apnoea } \\
\text { nealthy control }\end{array}$ \\
\hline Time & $\begin{array}{c}\text { OSAS diagnosis } \\
\text { night }\end{array}$ & $\begin{array}{c}\text { OSAS titration } \\
\text { night }\end{array}$ & Control subjects \\
\hline 23:00 h & $31.6 \pm 29.9$ & $20.16 \pm 10.3$ & $40.8 \pm 6.6$ \\
\hline 02:00 h & $47.4 \pm 33.8$ & $37.7 \pm 27.5$ & $70.6 \pm 14.1$ \\
\hline 06:00 h & $49.3 \pm 36.9$ & $35.6 \pm 37.9^{*}$ & $44.7 \pm 9.9$ \\
\hline
\end{tabular}

at $02: 00 \mathrm{~h}$. The reason is probably because on the CPAP titration night the pressure was increased progressively until the snoring and respiratory disturbances ceased; this was at approximately 03:30 h. It can be hypothesised that when optimal pressure was achieved $(03: 00 \mathrm{~h})$, and the patients were better oxygenated, the NE levels could decrease, resulting in lower melatonin levels.

It can be questioned whether it is reasonable to expect an immediate effect of CPAP treatment on melatonin levels. SUKEGAWA et al. [22] found a significant decrease in urinary catecholamine levels after one titration night in 17 OSAS patients; in this respect, the current authors think it is reasonable to expect this result in melatonin levels after one titration CPAP night.

BRATEL et al. [23] found a significant correlation between low pretreatment nocturnal $\mathrm{Sa}_{2} \mathrm{O}_{2}$ and high plasma and urinary NE levels in OSAS patients. In the present study, CPAP treatment reduced RDI, RAI and total sleep time with $\mathrm{Sa}_{2} \mathrm{O}_{2}<90 \%$ significantly. The current authors speculate that this CPAP treatment may decrease the NE levels and that is probably the reason why the melatonin decreased at 06:00 $\mathrm{h}$ in OSAS patients.

It is known that melatonin has sleep-promoting properties. ANTON-TAY et al. [4] observed that healthy volunteers fell asleep $20 \mathrm{~min}$ after melatonin administration. The current authors also speculate that OSAS patients may have higher melatonin level at 06:00 $\mathrm{h}$ in a metabolic response to increased sleep propensity and decreased sleep latency, as a result of attempts to increase the quantity of sleep because they have bad sleep quality [24].

Better sleep quality was not found in OSAS patients on the titration night. It is recognised that sleep efficiency, total sleep time, REM sleep and stage 3 and 4 sleep during a titration night is a complex set of variables impacted by the patient's response to $\mathrm{CPAP}$, the time needed to achieve ideal pressure, titration protocol and the technical capability of staff [25].

At this moment, the current authors must attribute the reduction in melatonin levels in OSAS patients to the reduction in respiratory disturbances. The cause of the morning somnolence in OSAS patients may be the higher melatonin level at 06:00 h on the diagnosis night, considering the sedative effects of melatonin. This finding, together with the increase in melatonin levels in the afternoon [10], could explain the daytime somnolence in
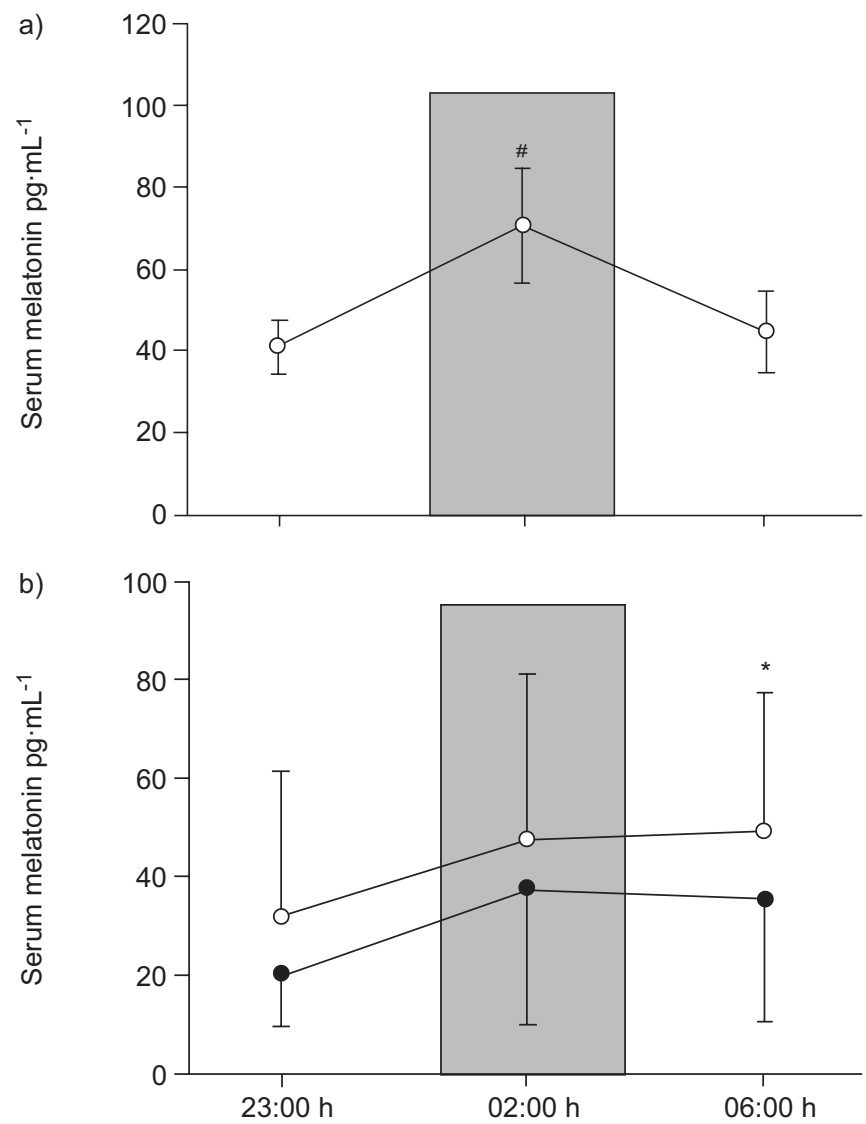

FIGURE 1. Serum melatonin concentration in a) healthy controls and b) obstructive sleep apnoea syndrome (OSAS) patients. The points at which blood was collected while the subjects were sleeping are shown ( $\square$ : dark phase, 02:00 h). Blood collection occurred while the subjects were awake (light phase) at 23:00 $\mathrm{h}$ and 06:00 h. Each point is presented as mean $\pm \mathrm{SD}$. $\bigcirc$ : OSAS patients on diagnosis night; $\bullet$ : OSAS patients on titration night. ${ }^{*}: p<0.0001$ between both light phases in healthy subjects; *: $\mathrm{p}<0.05$ at 06:00 h between diagnosis night and titration night.

OSAS patients, although other factors, such as intermittent hypoxia through the night and repeated sleep disturbance, are also likely to significantly contribute to this.

One possible criticism is that the effect of CPAP on melatonin levels has been studied on the CPAP titration night, when the optimal CPAP pressure is usually not achieved until 02:00 or 03:00 $\mathrm{h}$. Thus, the effect of CPAP optimal pressure can be seen only in the 06:00 $\mathrm{h}$ blood sample.

Another point of criticism is that it is known that a significant interindividual variability in melatonin levels can occur, independent of any medical condition, and this may affect the comparison of melatonin levels in the two different subject groups. However, the major finding of the present study was not a numerical comparison but the comparison of two melatonin secretion patterns.

The limitation of assessing melatonin at only three time-points across the night is present in the current study, but the blood samples for measurement of melatonin in the dark period were taken at 02:00 h, while the subjects were sleeping, and this is 
known to represent the maximal change from levels in the light period.

New studies in patients undergoing long-term CPAP treatment, with blood samples taken on a night that is not a titration night, would be of interest in order to draw out possible increases in sleep quality and the effect on melatonin levels in the first part of the night.

In conclusion, the present investigation shows that obstructive sleep apnoea syndrome patients did not show a melatonin peak value at midnight (dark period) with a decrease of melatonin levels at early morning (light period), unlike subjects without obstructive sleep apnoea syndrome, which do. Obstructive sleep apnoea syndrome patients had a plateau in melatonin levels in the second part of the night without the decrease at 06:00 $\mathrm{h}$ (light period). On the titration night, a decrease in melatonin levels was seen in the early morning (06:00 h; light period), making the melatonin secretion pattern of the second part of the night similar to subjects without obstructive sleep apnoea syndrome.

\section{REFERENCES}

1 Wetterberg L. Melatonin in humans. Physiological and clinical studies. J Neural Transm Suppl 1978; 13: 289-330.

2 Ganguly S, Coon SL, Klein DC. Control of melatonin synthesis in the mammalian pineal gland: the critical role of serotonin acetylation. Cell Tissue Res 2002; 309: 127-137.

3 Lewy AJ, Wehr TA, Goodwin RK, Newsome DA, Markey SP. Light suppresses melatonin secretion in humans. Science 1980; 210: 1267-1269.

4 Anton-Tay F, Diaz JL, Fernánez-Guardiola G. On the effect of melatonin upon human brain. Its possible therapeutic implications. Life Sci I 1971; 10: 841-850.

5 Kräuchi K, Cajochen C, Möri D, Graw P, Wirz-Justice A. Early evening melatonin and S-20098 advance circadian phase and nocturnal regulation of core body temperature. Am J Physiol 1997; 272: R1178-R1188.

6 Zeitzer JM, Dijk DJ, Kronauer R, Brown E, Czeisler C. Sensitivity of the human circadian pacemaker to nocturnal light: melatonin phase resetting and suppression. J Physiol 2000; 526: 695-702.

7 Arendt J, Bojkowski C, Franey C, Wright J, Marks V. Immunoassay of 6-hydroxymelatonin sulphate in human plasma and urine: abolition of the urinary 24-hour rhythm with atenolol. J Clin Endocrinol Metab 1985; 60: 1166-1173.

8 Kräuchi K, Cajochen C, Pache M, Flammer J, WirzJustice A. Thermoregulatory effects of melatonin in relation to sleepiness. Chronobiol Int 2006; 23: 475-484.

9 Lavie P, Lavie L, Herer P. All-cause mortality in males with sleep apnoea syndrome: declining mortality rates with age. Eur Respir J 2005; 25: 514-520.
10 Marti S, Sampol G, Muñoz X, et al. Mortality in severe sleep apnoea/hypopnoea syndrome patients: impact of treatment. Eur Respir J 2002; 20: 1511-1518.

11 Lacasse Y, Godbout C, Sériès F. Health-related quality of life in obstructive sleep apnoea. Eur Respir J 2002; 19: 499-503.

12 Wikner J, Svanborg E, Wetterberg L, Röjdmark S. Melatonin secretion and excretion in patients with obstructive sleep apnoea syndrome. Sleep 1997; 20: 1002-1007.

13 Ulfberg J, Micic S, Strom J. Afternoon serum-melatonin in sleep disordered breathing. J Intern Med 1998; 244: 163-168.

14 Brzecka A, Piesiak P, Zareba-Bogdał E, Zierkiewicz G, Plamieniak Z. Rhythm of melatonin excretion in obstructive sleep apnoea syndrome. Pneumonol Alergol Pol 2001; 69: 650-654.

15 Reiter RJ. Pineal melatonin: cell biology of its synthesis and of its physiological interactions. Endocr Rev 1991; 12: 151-180.

16 Elmasry A, Lindberg E, Hedner J, Janson C, Boman G. Obstructive sleep apnoea and urine catecholamines in hypertensive males: a population-based study. Eur Respir J 2002; 19: 511-517.

17 Heitmann J, Ehlenz K, Penzel T, et al. Sympathetic activity is reduced by nCPAP in hypertensive obstructive sleep apnoea patients. Eur Respir J 2004; 23: 255-262.

18 Montserrat JM, Amilibia J, Barbé F, et al. Tratamiento del síndrome de apneas-hipopneas durante el sueño. [Treatment of sleep apnea-hypoapnea syndrome]. Arch Bronconeumol 1998; 34: 204-206.

19 Rechtschaffen A, Kales AA, eds. A Manual of Standardized Terminology, Techniques and Scoring System for Sleep Stages of Human Subjects. NIH Publication No. 204. Washington, Government Printing Office, 1968.

20 Manz B, Seidel A, Alexander H, et al. Development and validation of a radioimmunoassay for serum melatonin. $J$ Clin Chem Clin Biochem 1989; 27: 797-802.

21 Wetterberg L, ed. Light and Biological Rhythms in Man. Oxford, Pergamon Press, 1993.

22 Sukegawa M, Noda A, Sugiura T, et al. Assessment of continuous positive airway pressure treatment in obstructive sleep apnea syndrome using 24-hour urinary catecholamines. Clin Cardiol 2005; 28: 519-522.

23 Bratel T, Wennlund A, Carlström K. Pituitary reactivity, androgens and catecholamines in obstructive sleep apnoea. Effects of continuous positive airway pressure treatment (CPAP). Respir Med 1999; 93: 1-7.

24 Burgess HJ, Sletten T, Savic N, Gilbert SS, Dawson D. Effects of bright light and melatonin on sleep propensity, temperature, and cardiac activity at night. J Appl Physiol 2001; 91: 1214-1222.

25 Drake CL, Day R, Hudgel D, et al. Sleep during titration predicts continuous positive airway pressure compliance. Sleep 2003; 26: 308-311. 